P\&A Año 3, N. ${ }^{\circ} 5$

julio-diciembre 2018

pp. [79]-88

\title{
Resumen
}

La presente investigación toma la percepción como el punto de partida para analizar la imagen urbana, estudiando de esta forma la ciudad y sus componentes. A partir de la metodología de mapas mentales y el arte de los mapas diseñados por Paula Scher, en la asignatura Diseño Gráfico de la Facultad de Arquitectura y Urbanismo, se exploró la representación de la percepción urbana distrital de los estudiantes a través del color y elementos visuales significativos. Los resultados mostraron impacto visual, contraste, originalidad, identificación de percepciones urbanas individuales y grupales, e información urbana como áreas peligrosas, áreas recreativas y otras zonas significativas.

Palabras clave: Mapas mentales, representación gráfica, percepción urbana, arte

\section{Aprender a mapear la ciudad: Arte y percepción*}

Learning to map the city: Art and perception

\author{
Est. Ms. Arq. Alexander Galvez Nieto**
}

Recibido: 9 de enero de 2018

Aceptado: 22 de mayo de 2018

\begin{abstract}
This investigation assumes perception as the starting point to analyze the urban image, studying in this way the city and its components. Based on the methodology of mental maps and the art of maps designed by Paula Scher, in the Graphic Design course of the Architecture and Urbanism Faculty, the representation of the students' district urban perception through color and significant visual elements was explored. The results showed visual impact, contrast, originality, identification of individual and group urban perceptions, and urban information such as dangerous areas, recreational areas and other significant areas.
\end{abstract}

Keywords: mental maps, graphic representation, urban perception, art

\footnotetext{
* El documento corresponde a la experiencia del autor, en el desarrollo del tema dentro de la asignatura Diseño Gráfico, y su interés en el campo de la representación gráfica.

** Arquitecto por la Universidad Ricardo Palma. Técnico en Gráfica Publicitaria (Instituto Toulouse Lautrec). Maestro en Docencia Superior (Escuela de Posgrado Universidad Ricardo Palma). Egresado de la maestría en Arquitectura y Sostenibilidad (Escuela de Posgrado Universidad Ricardo Palma). Docente en la Facultad de Arquitectura y Urbanismo de la Universidad Ricardo Palma.
} 


\section{Introducción}

Dentro del estudio de las percepciones se encuentra la percepción urbana, tomada para esta experiencia, la cual según Ceniceros (2014) "se refiere al efecto de recoger y captar la información aportada por la ciudad". La ciudad se transforma con el tiempo, junto con sus habitantes, y es por esta razón que los estudios sobre la percepción de la ciudad deben realizarse cada cierto corto tiempo, para tener una información actualizada. La percepción es un proceso que permite al habitante urbano conocer e intervenir en su ambiente, y como interfiere en el comportamiento de las personas en la ciudad.

Para Ávila (citado por Ceniceros, 2014) la percepción es "una herramienta para reconocer y actuar en la ciudad, como un mecanismo de acercamiento del individuo a su entorno, se puede lograr una base de elementos que son reconocidos por los habitantes de la ciudad" (p.21). El espacio vivido es subjetivo porque depende de las características personales y experiencias sociales de cada persona. La exploración del espacio puede realizarse a partir de la aplicación de diversas técnicas metodológicas, como: los mapas mentales, definidos como traducciones genéricas del ser y sentir de los individuos (Pinassi y Seguí, 2016).

Kevin Lynch, fue pionero en los trabajos de percepción del espacio urbano, señalando que son resultado de "la sensación inmediata y del recuerdo de experiencias anteriores, y se utiliza para interpretar la información y orientar la acción" (citado por Fernández y García, 1993).

La aplicación de este método en la enseñanza fue establecida por Catling en 1978, como instrumento de diagnóstico, para determinar el nivel de desarrollo espacial de los alumnos y su capacidad de representación de un entorno familiar; y como fuente de información a fin de conocer cuáles son los diversos elementos significativos en las imágenes mentales de un grupo de estudiantes. (Fernández y García, 1993, p.47)
La aplicación de este método en la enseñanza fue establecida por Catling en 1978, como instrumento de diagnóstico, para determinar el nivel de desarrollo espacial de los alumnos y su capacidad de representación de un entorno familiar; y como fuente de información a fin de conocer cuáles son los diversos elementos significativos en las imágenes mentales de un grupo de estudiantes (Fernández y García, 1993, p.47).

Los medios de recolección de información son importantes para la producción de conocimiento y diseño. Estos medios deben ser sencillos y abiertos para que todos puedan participar (Paisaje Transversal, 2018). Un mapa es la representación gráfica del espacio público, que muestra detalles que los usuarios no pueden recordar y permite situar los aspectos más significativos de la ciudad. Muchos estudios de mapas de distintos tipos se han desarrollado en el mundo para la comprensión del espacio urbano y de las percepciones de la realidad física que tienen los habitantes.

\section{La imagen bidimensional del espacio urbano}

Todos tienen un mapa mental del recorrido a casa, del barrio, de la ciudad, e incluso del país. A este mapa mental otros autores lo denominan como: imagen espacial, mapa cognitivo, esquema espacial, mapa psicológico, representación topográfica, atlas mental, entre otros. Marchesi (citado por Campos, Perez y Tarrío, 2015) define el mapa cognitivo como "la representación interna que el individuo tiene sobre su ambiente (o sobre parte de él) y que le permite orientarse en el mismo"(p.146). Como manifiesta Alba (citado por Pinassi y Seguí, 2016), "el concepto de mapa no tiene un significado cartográfico, sino únicamente semántico"; es la representación de la imagen del valor simbólico o subjetivo que la persona confiere a un lugar (Pinassi y Seguí, 2016).

El estudio de los mapas mentales basados en preferencias se debe al importante aporte del geógrafo británico Peter Gould, bajo el paradigma de la Geografía Humanista en el análisis 
de la percepción, quien lo considera un tema fundamental en el análisis del espacio en diversas escalas, ya que las decisiones espaciales de las personas se basan principalmente en su entorno percibido en lugar del entorno físico real (Bunzai, 2011; Pinassi y Seguí, 2016). Así se puede observar el alcance multidisciplinario del tema: El mapa mental es un resultado psicológico relacionado con el espacio.

Bunzai (2011) representa el proceso del mapa mental de la siguiente manera: La realidad física es la base empírica que imprime diferentes estímulos a las personas. A través de la percepción individual se genera una imagen mental que es representada gráficamente a través de un mapa mental (Figura 01).

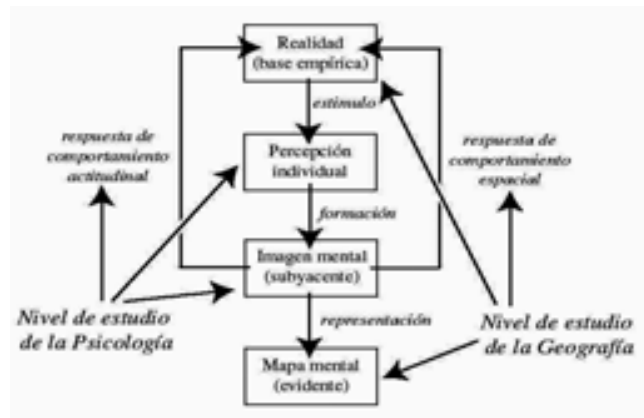

Figura 1. Proceso del mapa mental y ámbitos de estudio (Buzai, 2011).

Otra diferencia entre los estudios radica en la formación de los autores. Por ejemplo, según Campos, Perez y Tarrío (2015), los geógrafos se centran en la historia de la ciudad, en estudios descriptivos tanto de edificios, personas y sus costumbres. De otro lado, los psicólogos se centran en aspectos cognitivos y en los elementos que forman el mapa cognitivo. Los arquitectos, por su parte, se fijan más en cómo los individuos perciben y sienten la ciudad en su conjunto, y en sus elementos: edificios, plazas, calles, etc.

Basándose en la teoría acerca de la imagen desarrollada por el artista y teórico húngaro György Kepes, el planificador urbano Kevin Lynch realiza estudios sobre las imágenes urbanas. Lynch veía al diseño urbano como un arte visual de larga escala temporal y que no podía ser percibido en su totalidad en un mismo momento, todo elemento es identificado por sus contornos (Buzai, 2011).

Las imágenes mentales de los personas se aprecian mediante representaciones que son generadas a través de su percepción del lugar (Ceniceros, 2014). Otra característica sobre los mapas cognitivos de las ciudades es que su validez se reduce a un momento específico, aunque existen algunos elementos urbanos que no varían su importancia con el tiempo.

Casi todas las técnicas de elaboración de los mapas mentales o cognitivos están condicionadas por sus habilidades espaciales y cognitivas de los sujetos y su dominio de otras técnicas. La técnica más utilizada, por su fácil aplicación, es el dibujo de la ciudad (barrio o casa). El dibujo debe contener las calles, edificios significativos, y todo aquello que se considere importante. Alguien en el dibujo podría dejar ciertos elementos fuera, mientras otras personas las incluiría por su significado subjetivo asignado (Campos, Perez y Tarrío, 2015).

Otros métodos de representación pueden ser: el reconocimiento de fotografías, el recuerdo libre y la realización de maquetas. El funcionamiento es el mismo: señalar sobre la representación gráfica las propuestas, valores y problemáticas que merecen atención.

Más allá de su denominación: mental o cognitivo; en cada trabajo se debe analizar su significado, entender el mundo interior, qué espacios se valoran en una ciudad, los límites de los lugares, el valor de los espacios recreativos y patrimoniales, etc.

\section{Los mapas de Paula}

La diseñadora gráfica Paula Scher basa sus diseños en el uso de la letra, dando productos innovadores, emocionales y atractivos. Paula afirma que sus mejores ideas las obtiene cuando viaja en taxi, en pleno tráfico: "Permito que mi subconsciente se apodere de mí para poder asociar libremente" (párr.11). De hecho en la década de 1990, 


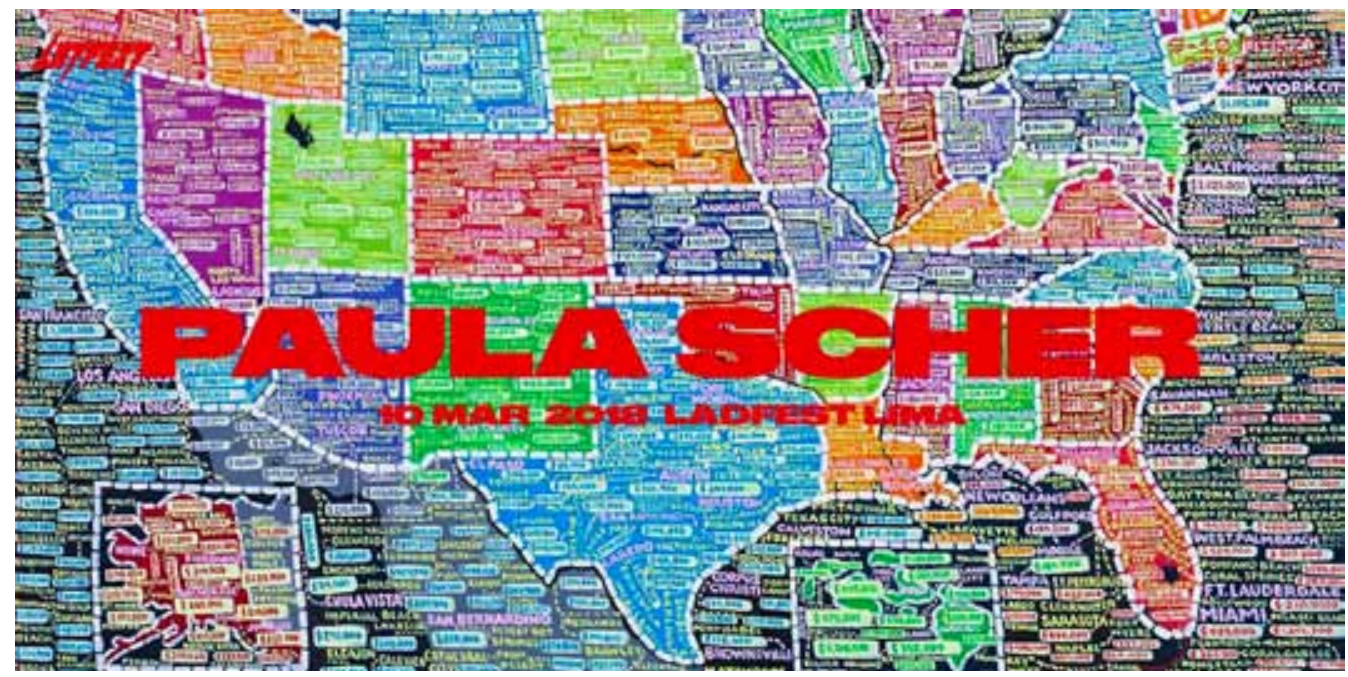

Figura 2. Aviso del LATFEST 18 anunciando la participación de Paula Scher (Latin American Design, 2018)

se percató que ya no empleaba sus manos para nada y las echaba de menos. De modo que empezó a pintar (Fernández, 2017).

Unos de sus mejores y más complicados trabajos, son unos mapas grandísimos y a escala. Comenzó a pintar coloridos mapas del mundo, pero no con herramientas del cartógrafo, sino con palabras letras y caracteres tipográficos: continentes, países, islas, océanos, ciudades y barrios (Figura 02). Los accidentes geográficos son sustituidos por un enredo de palabras (Experimenta, 2011). Scher (citada por Lubrano, 2010) decía: “Mi padre siempre me decía que no existían mapas correctos: para él mejorarlos era una misión" (párr.2). Y es que el padre de Scher fue unos de los investigadores más destacados de la cartografía moderna. Paula, sin embargo, diseña los mapas a su modo y, para ello, utiliza las palabras.

Para Scher, la cartografía es una abstracción imperfecta donde las palabras e imágenes de sus mapas expresan un mundo subjetivo. Por ejemplo, en uno de sus mapas, Sudamérica es coloreada con colores tropicales y Manhattan parece ser un espacio atiborrado (Experimenta, 2011). Su uso del color es preciso, llamativo, con presencia de grandes contrastes (Figura 03). "Está claro que son mapas $100 \%$ inexactos,... porque en ellos siempre ahonda en lo que realmente le interesa resaltar; la complejidad y la contrariedad de las ciudades en que habitamos. Un mundo en constante proceso de cambio" (Gráffica, 2011). El paisaje se transfigura por los mismos nombres de sus ciudades, ríos, mares y cadenas de montañas; donde el error se convierte en peculiaridad y contribuye a hacer aún más única una obra que tiene precedentes en la historia del arte (Lubrano, 2010).

Las fuentes en las que se inspira son las de la familia Sans-Serif o de palo seco, con corte sin perifollos para optimizar la legibilidad rigurosamente en letra de imprenta (Lubrano, 2010). Mostrándose así un poder comunicador en la tipografía. El carácter varía su significado en función a su peso o altura. Por ejemplo, si el carácter pertenece a una fuente pesada refiere inmediatez, pero si tuviese un trazo fino y serif alude a lo clásico (Fernández, 2017).

Lubrano (2010) señala que aunque asume dimensiones de unas medidas exageradas, que incluso inculca temor a la vista, pero también invita a acercarse y a embarcarse a un mundo globalizado conocido. Scher dice: "La escala distorsionada, los errores de ortografía: todo contribuye a mi prospectiva única del mundo" (Lubrano, 2010, párr.5).

\section{La respuesta de los estudiantes de ar- quitectura}

En esta experiencia participaron dos grupos de 20 estudiantes de la asignatura Diseño Grá- 
fico de la Facultad de Arquitectura y Urbanismo, perteneciendo un grupo al ciclo académico 2017-II y el otro grupo, al ciclo académico 2018-I. La selección de estudiantes es por el proceso de inscripción de estudiantes, a partir del quinto ciclo académico de la carrera debido a la estructura curricular de la facultad.

El objetivo que guía la experiencia consiste en: analizar la representación gráfica de la percepción del espacio urbano de los estudiantes de arquitectura a partir de la metodología de mapas mentales o cognitivos, y el uso del color y elementos visuales significativos.

En el grupo de estudiantes del ciclo académico 2017-II se usó un mapa perimetral de un distrito de Lima Metropolitana para cada estudiante, de preferencia en el que viviera o conociera de antemano, sin repetir entre ellos. El tamaño del mapa variaba de acuerdo a la extensión territorial del distrito, se les presentó en color blanco. En dichos mapas debían señalar las vías principales en color gris. Además los estudiantes debían escribir en una hoja los lugares importantes que reconocían en el distrito y como se los hacían sentían dichos lugares.

Una vez recogidos los datos, a través de la técnica del collage comenzó a identificarse las distintas zonas sensoriales que se identificó en el distrito, a través de trozos de papel reciclado de colores. El rojo simbolizaba el peligro en la ciudad, el verde representaba las áreas recreativas y naturales, el lila representaba el reposo y la meditación, el anaranjado representaba el ladrillo expuesto, el material de las viviendas precarias; el amarillo, la alegría y el azul, las zonas de negocios. La materialidad del trabajo ayudó a generar contrastes y texturas en la representación gráfica de los mapas mentales (Figura 04).

El primer resultado obtenido en esta primera experiencia fue que los estudiantes tuvieron un recuerdo muy vago de las zonas del distrito. Solo ubicaban las que mayormente transitaban en su día a día. Sobre la identificación de vías, fueron mucho más abstrac- tos y esquematizaron rápidamente las vías principales del distrito. El reconocimiento de otras zonas del distrito fue apoyado con fotografías y búsqueda de información del lugar.

Lo importante de esta experiencia no fue solo reconocer las percepciones que causaban las variopintas zonas de los distritos limeños, sino además eran verlas en su totalidad, con todos los distritos ensamblados, formando la gran Lima Metropolitana. Así en conjunto, podían los estudiantes observar que en los límites de los distritos muchas veces las sensaciones se prolongaban y hacía que se diluyera el límite físico del distrito viéndose como una gran unidad. De igual manera muchos de los estudiantes identificaban similares sus percepciones con respecto a las sensaciones representadas en otros distritos que ellos no habían realizado.

En el otro grupo de estudiantes del ciclo académico 2018-I, también se trabajó sobre algunos distritos de Lima Metropolitana. Los distritos que se abordaron fueron Barranco, Cercado de Lima y Pueblo Libre. En esta ocasión los mapas fueron abordados por grupos formados de 3 o 4 estudiantes. Y hubo dos grupos por cada distrito asignado para, al final, hacer una comparación ente grupos del mismo distrito y ver similitudes y diferencias en la representación de la imagen mental urbana. Se usó un mapa con el delineado de manzanas y vías del distrito asignado por grupo. La elección del distrito a los grupos fue al azar. El tamaño del mapa se inscribía en un formato 40 x $40 \mathrm{~cm}$.

En dichos mapas debían señalar a través de líneas, formas, colores y textos sobre los fenómenos que percibían que sucedían en el distrito. Estos fenómenos podían ser sociales, urbanos, ambientales, recreativo, culturales o de cualquier otra índole.

Los datos iban a ser recogidos a través de la técnica del drawing layered, una técnica artística que consiste en superponer varias capas de base transparente para formar un todo unitario. Utilizaron papel de colores, 


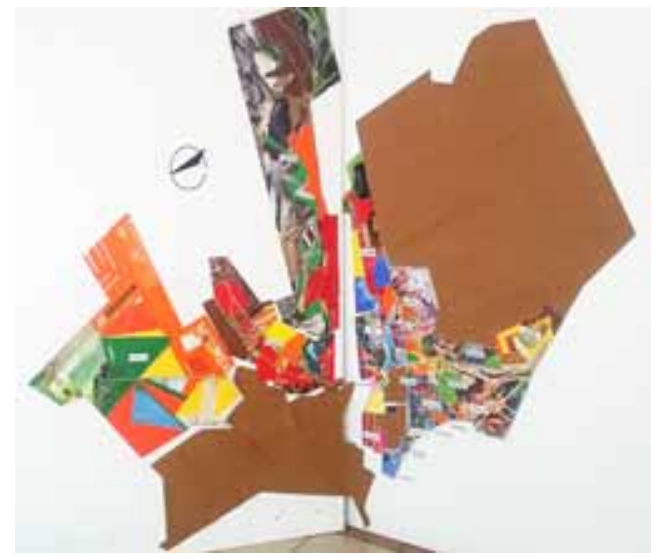

Figura 3. Mapa mental de algunos distritos de Lima Metropolitana-Lima te veo (Asignatura Diseño Gráfico URP-Semestre 2017-II, por todos los estudiantes de la asignatura)

dibujos a mano, plumones, micas transparentes sobre las capas para identificar estos fenómenos en el distrito. Se tuvo en consideración el significado de las líneas, formas y del color para la representación gráfica.

En esta experiencia el trabajo colaborativo ayudó de primera mano para tener un panorama más completo del distrito asignado (Figura 05). Se apoyaron además con visitas de campo, búsqueda de información y fotografías.

En los grupos del distrito de Cercado de Lima, por ejemplo:

Uno de los grupos a través de la forma y grosor de líneas identificó el cambio de la trama urbana que el distrito atravesó desde sus orígenes. También visualizó como amenaza la aparición de nuevas edificaciones en perjuicio de las edificaciones patrimoniales y en reemplazo de otras edificaciones antiguas.

El otro grupo, más bien, hizo énfasis en la aglomeración de las personas en distintas zonas del distrito, en la indicación de edificaciones patrimoniales, de las principales vías del distrito y las vías perimetrales del mismo. Lo interesante es que para cada indicación se recurrió a diferentes elementos: las aglomera- ciones fueron indicadas por círculos anaranjados de diferentes tamaños, las edificaciones patrimoniales en figuras esquemáticas tridimensionales y las vías señaladas a través de letras, con los nombres de las vías respectivas en diferentes tamaños. Esta última estrategia también se aplicó con la señalización del Rio Rímac, con el uso de tipografía en color gris.

En los mapas mentales del distrito de Barranco:

Un grupo identificó tribus urbanas por zonas, nombradas por los autores como: barril sin fondo, cultura hippie, cultura chupística y epifanías, es decir las zonas de venta de comida, de venta de pulseras y accesorios, bares y discotecas, y de lugares tradicionales; respectivamente. Este grupo a través de hilos de color superpuestos señaló las dinámicas de cada tribu identificada, viéndose como una gran red compleja de actividades en el distrito: El hilo rojo para la zona de comidas, el hilo verde para la cultura hippie, el hilo amarillo para la zona de bares y el hilo marrón para la zona tradicional.

El otro grupo identificó el corazón del distrito en el casco antiguo del distrito y las vías principales como las arterias que transportan el tránsito de las personas y el tráfico de los vehículos.

En el caso de los grupos de Pueblo Libre, sus representaciones fueron más abstractas. Ambos grupos enfocaron sus representaciones, de manera distinta, sobre la historia y cultura del distrito. Ambas muestras fueron muy coloridas y usaron iconografía representativa del distrito:

Un grupo representó la historia del distrito, desde sus épocas de grandes viñedos, la sangre derramada por las guerras, las siluetas de los libertadores José de San Martin y Simón Bolívar y sus sueños de un nuevo futuro quienes residieron ahí, la trama urbana actual y la presencia de nuevos edificios multifamiliares.

El otro grupo a través de su famoso árbol ombú del distrito, muestra su cultu- 

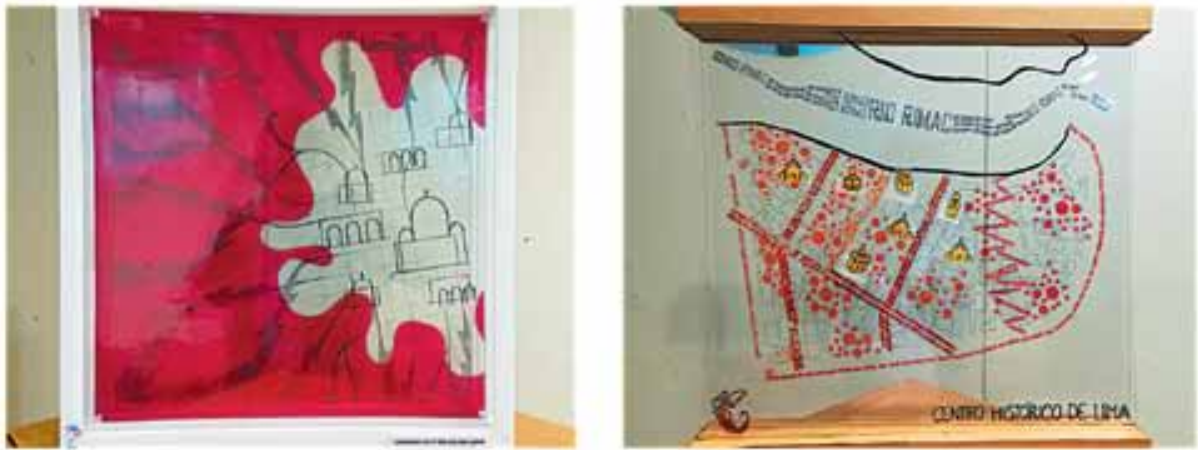

\section{Cercado de Lima}
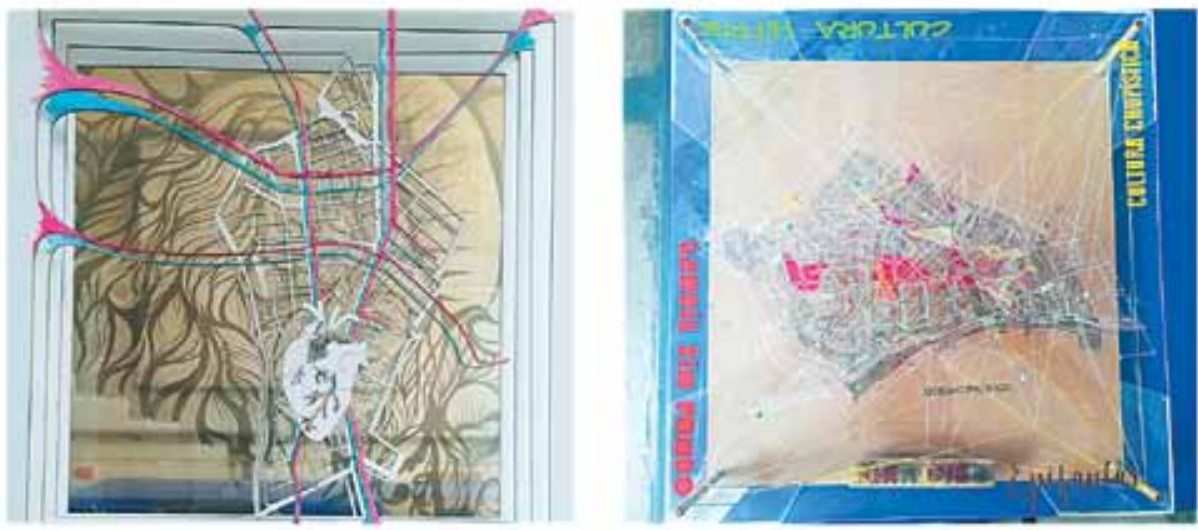

\section{Barranco}
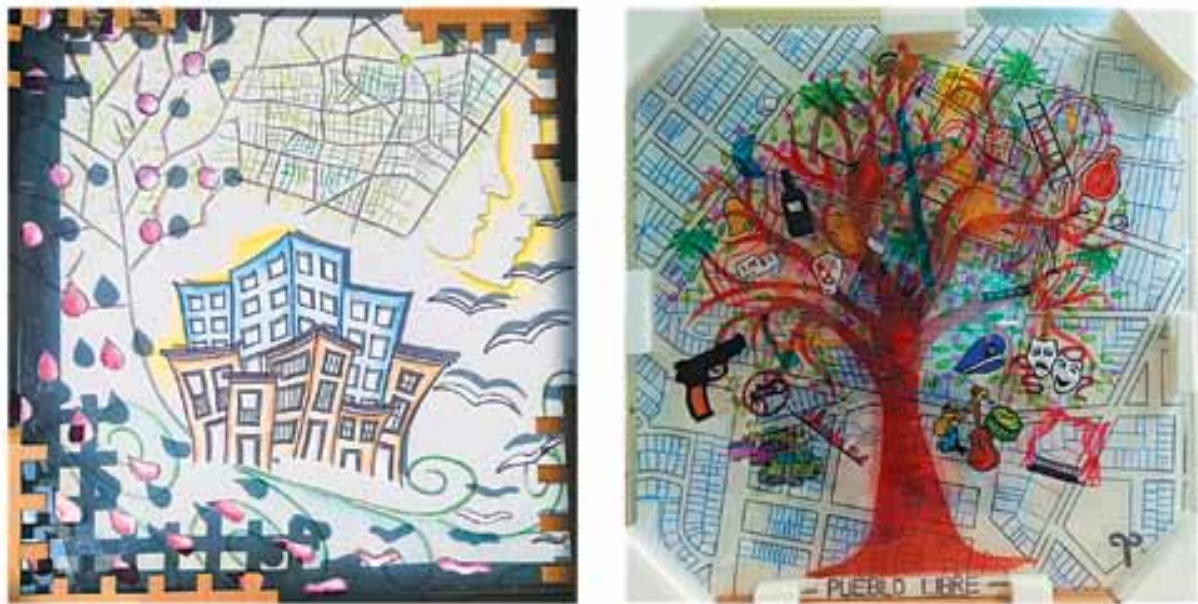

\section{Pueblo Libre}

Figura 3. Propuestas grupales de los mapas mentales de los distritos de Cercado de Lima, Barranco y Pueblo Libre (Asignatura Diseño Gráfico URP-Semestre 2018-I, por todos los estudiantes de la asignatura)tre 2017-II, por todos los estudiantes de la asignatura) 
ra con iconografía representativa de su tradición (como el vino, la taberna, la municipalidad), sus problemas (inseguridad, delincuencia, basura) $\mathrm{y}$, por otro lado, sus fortalezas (teatro, música criolla).

La materialidad del trabajo ayudó a generar impacto visual y contrastes en la representación gráfica del mapa mental. En este trabajo a diferencia del ciclo académico anterior, el dibujo era uno de los pilares para su desarrollo. Otro dato importante es que se le indicó a todos los estudiantes a emplear material reciclado en la medida posible. Los estudiantes pudieron experimentar otra manera de representar los mapas mentales urbanos, de una manera más lúdica y de mayor impacto visual. Les permitió conocer con más detalle el distrito e identificar zonas específicas con ciertas actividades particulares.

\section{Reflexiones}

La elaboración de mapas mentales sobre la percepción de la imagen urbana, además que está comprobado que es un excelente instrumento didáctico para conocer la subjetividad de quien lo elabora, constituye un medio para expresar de manera libre y creativa dicha imagen mental, haciéndose valer de técnicas y materiales diversos.

Paula Scher no intenta hacer representaciones de mapas reales, sino ella también a través de la pintura en muros o supergrafía, nos muestra cómo percibe los lugares, las sociedades de su país y del mundo. Y ella lo hace a través del color y su obsesión por la tipografía. Su interpretación del mundo nos permite tomar un enfoque diferente de apreciar los mapas y el trabajo gráfico a escala. Su propuesta es innovadora y fresca, que hace preguntar cuáles son los límites de la representación de un mapa mental. Scher nos hace replantear un mapa que contiene calles, parques, plazas y edificaciones; por un mapa que albergue letras, números, formas y colores.

Inspirándose en la experiencia de Scher, durante los ciclos académicos anteriormente mencionados a través de técnicas artísticas como el collage o el drawing layered y el ma- nejo de conceptos como el significado de las líneas, formas y color, se representó la percepción de la imagen urbana de manera individual o grupal.

Lo interesante de ambas experiencias, a pesar de las diferencias de estudiantes y de los procesos para la ejecución de los trabajos, es que existen dos puntos a considerar:

La aplicación de conceptos de línea, forma y color para el logro de un impacto visual: Este ítem es importante porque se alinea con el desarrollo de una de las capacidades principales contempladas en la resolución de la asignatura, introducir al tema del conocimiento de lenguaje y comunicación visual para el desarrollo de la capacidad creativa. El trabajo de los mapas mentales sirve de pretexto para poner en práctica el conocimiento adquirido y construir estrategias que permitan una composición equilibrada y de alto impacto visual positivo.

La toma de decisión del tipo de trazo de líneas, la selección de formas a componer y el color a usar en las líneas, formas y fondo; es la base para la comunicación del mensaje de la imagen mental a desear trasmitir.

Discusión final de todos los trabajos con la clase: A través de la discusión en clase se puede reconocer algunos aspectos perceptuales con respecto a distritos que no conoce el estudiante, además de visualizar estrategias diferentes que son tomadas por los compañeros de clase, permitiendo identificar fortalezas y debilidades en los procesos de representación propios y ajenos. Realizar mapas mentales se alinea con el perfil de egresado del estudiante de arquitectura en el sentido de formar su cultura humanista, en cuanto favorece el desarrollo de su dimensión comunicativa debido a la representación de significados y la exploración de la interpretación e interacción con otros individuos; y el desarrollo de su dimensión estética por la apreciación de la belleza, desde su capacidad de sentir su entorno.

El trabajo a mano es un valor agregado en el aspecto educativo que debe considerarse. Los procesos de representación análoga, a diferencia de la digital, favorece una mayor 
conexión con el trabajo a escala en primera instancia. A través del tacto se inicia la construcción mental de la realidad en forma directa y constante. El tacto es importante para la percepción espacial y su representación. Por esta razón, el modo de desarrollar mapas mentales, recurre a técnicas a mano o análogas como el dibujo o la pintura, porque permite llevar a dos dimensiones fácilmente la idea que se tiene sobre el espacio urbano.

Y no solo los mapas mentales deberían ser estudiados como instrumentos didácticos y psicológicos, sino también como instrumentos de diseño gráfico, como exploración del campo de la representación gráfica del ser humano. La representación es un proceso de traducción de ideas y es el fundamento del desarrollo humano. Y esta actividad, en el campo intelectual, es un instrumento valioso y creativo para el arquitecto. Estudiar las técnicas de representación y los materiales a emplear pueden constituir un aporte valioso al rubro.

Por eso es importante que este tipo de actividades se celebren en el proceso de enseñanza aprendizaje del estudiante de arquitectura. Invitar al estudiante a explorar diferentes técnicas, diferentes situaciones y retos que afrontar, para plantearse nuevas estrategias para buscar soluciones creativas. Y en este proceso el estudiante va construyendo conocimiento nuevo en base a los conceptos iniciales brindados.

En el campo del diseño, sea gráfico, arquitectónico o de cualquier índole, nada está escrito. Existen muy pocos trabajos académicos en relación a estas cuestiones, es por ello que este tipo de experiencias didácticas enriquecen la base de conocimiento para futuras exploraciones, asumir las fortalezas y corregir las debilidades. Nuevos caminos se abren en el campo de la representación gráfica, y depende de los docentes presentar a los estudiantes; situaciones desafiantes, motivadoras, más innovadoras y basadas en una realidad que el estudiante puede tener fácil acceso. Esto constituye ser parte de una educación innovadora y propia que los actuales tiempos exigen para la formación multidimensional del profesional. 


\section{Referencias}

Buzai, G. (2011). La construcción de mapas mentales mediante apoyo geoinformático. Desde las imágenes perceptivas hacia la modernización digital. Revista geográfica de Valparaíso, (44), 1-17. Recuperado de https://dialnet.unirioja.es/descarga/ articulo/5511035.pdf

Campos, D.; Pérez, M. \& Tarrío, S. (2015). El mapa cognitivo de los estudiantes de Bellas Artes II: El conocimiento del centro histórico de Pontevedra. Revista de estudios e investigación en Psicología y Educación, Extr.(1), 146-150. Recuperado de http:// revistas.udc.es/index.php/rei

pe/article/view/reipe.2015.0.01.685

Ceniceros, B. (2014). Imagen urbana y espacios vacíos de ciudad Juárez, Chihuahua. De la percepción social hacia una propuesta de intervención urbano-artística. Chihuahua, México: Colegio de la Frontera Norte.

Fernández, E. (2017). Unir Revista. La Rioja: Universidad Internacional de La Rioja. Recuperado de https://www.unir.net/marketing-comunicacion/ revista/noticias/el-diseno-grafico-de-paula-scher-oel-amor-por-la-tipografia/549201752277/

Fernández, F. \& García, C. (1993). Los mapas mentales como fuente de información sobre la imagen urbana. Una aplicación práctica. Revista de la Facultad de Educación de Albacete, (8), 45-57. Recuperado de https://dialnet.unirioja.es/servlet/ articulo? codigo $=2282487$
Gráffica. (2014). Gráffica. Valencia, España: Palaugea Comunicación. Recuperado de https:/graffica.info/ los-mapas-tipograficos-de-paula-scher/

Experimenta. (2011). Experimenta. Madrid, España: Editorial Experimenta. Recuperado de https://www. experimenta.es/noticias/grafica-y-comunicacion/ paula-scher-mapas-de palabras-3199/

Lubrano, F. (2010). Cafébabel. Paris, Francia: Babel International. Recuperado de https://cafebabel.com/ es/article/paula-scher-cuando-la-frontera-es-lapalabra-5ae005c8f723b35a145df863/

Paisaje Transversal. (2018). Archdaily. Perú: Plataforma Networks. Recuperado de https://www. archdaily.pe/pe/889402/que-herramientas-tenemospara-disenar-de-forma-colaborativa-el-espaciopublico

Pentagram. (2018). Pentagram. Estados Unidos. Recuperado de https://www.pentagram.com/work/ paula-scher-maps

Pinassi, C. \& Seguí, M. (2016). Representación del espacio urbano en alumnos de primaria de la ciudad de Bahía Blanca (Argentina). Un análisis a partir de mapas mentales. Boletín de la Asociación de Geógrafos Españoles, (72), 349-380. Recuperado de https:// dialnet.unirioja.es/servlet/articulo?codigo $=5757001 \mathrm{v}$ 